Natural Hazards and Earth System Sciences (2001) 1: 113-118

(C) European Geophysical Society 2001

\title{
Ionospheric phenomena before strong earthquakes
}

\author{
A. S. Silina ${ }^{1}$, E. V. Liperovskaya ${ }^{1}$, V. A. Liperovsky ${ }^{1}$, and C.-V. Meister ${ }^{2}$ \\ ${ }^{1}$ Institute for Physics of the Earth, Moscow, Russia \\ ${ }^{2}$ Project Space Plasma Physics, Potsdam, Germany
}

Received: 7 June 2001 - Revised: 28 September 2001 - Accepted: 5 November 2001

\begin{abstract}
A statistical analysis of several ionospheric parameters before earthquakes with magnitude $M \geq 5.5$ located less than $500 \mathrm{~km}$ from an ionospheric vertical sounding station is performed. Ionospheric effects preceding "deep" (depth $h>33 \mathrm{~km})$ and "crust" $(h \leq 33 \mathrm{~km})$ earthquakes were analysed separately. Data of nighttime measurements of the critical frequencies $f o \mathrm{~F} 2$ and $f o \mathrm{Es}$, the frequency $f b$ Es and Es-spread at the middle latitude station Dushanbe were used. The frequencies $f o \mathrm{~F} 2$ and $f b \mathrm{Es}$ are proportional to the square root of the ionization density at heights of $300 \mathrm{~km}$ and $100 \mathrm{~km}$, respectively. It is shown that two days before the earthquakes the values of $f o \mathrm{~F} 2$ averaged over the morning hours (00:00 LT-06:00 LT) and of $f b \mathrm{Es}$ averaged over the nighttime hours (18:00 LT-06:00 LT) decrease; the effect is stronger for the "deep" earthquakes. Analysing the coefficient of semitransparency which characterizes the degree of small-scale turbulence, it was shown that this value increases 1-4 days before "crust" earthquakes, and it does not change before "deep" earthquakes. Studying Es-spread which manifests itself as diffuse Es track on ionograms and characterizes the degree of large-scale turbulence, it was found that the number of Es-spread observations increases 1-3 days before the earthquakes; for "deep" earthquakes the effect is more intensive. Thus it may be concluded that different mechanisms of energy transfer from the region of earthquake preparation to the ionosphere occur for "deep" and "crust" events.
\end{abstract}

\section{Introduction}

The interest in electromagnetic and ionospheric phenomena caused by processes in the lithosphere which are related to earthquake preparation increased during the last ten years. General results of recent works on the subject were presented at conferences in Japan (Hayakawa and Fujinawa, 1994; Hayakawa, 1999), and in monographs and reviews (Gokhberg

Correspondence to: C.-V. Meister (cvmeister@aip.de) et al., 1995; Liperovsky et al., 1992, 2000a). As the number of earthquakes with magnitude $M \geq 4.5$ is rather large, for these events usually a statistical analysis of the phenomena preceding them was performed. But precursor effects of stronger earthquakes with $M \geq 6.0$ were analysed separately, as these earthquakes are rare and a statistical analysis is quite impossible (Pulinets, 1998; Hayakawa, 1999; Ondo, 2000). It should be pointed out that in studies of ionospheric precursors of earthquakes usually the dependence of seismoionospheric effects on the distance from the hypocenter to the vertical sounding station was considered. A dependence on the depth of the epicenter was not examined. Ionospheric effects were revealed not more than 1-5 days before the earthquakes, and usually 2-3 days before the earthquakes with magnitudes $M \leq 5.5$, post seismic influences exist about 1-2 days after the earthquakes (Hayakawa and Fujinawa, 1994; Gokhberg et al., 1995; Liperovsky et al., 1992, 2000a; Hayakawa, 1999).

In the present paper, an attempt of a statistical analysis of ionospheric effects 6 days before and 2 days after the earthquakes with $M \geq 5.5$ is presented. The analysis of the temporal dependence of the parameters of the ionosphere was performed separately for so-called "deep" $(h>33 \mathrm{~km})$ and "crust" ( $h \leq 33 \mathrm{~km}$ ) earthquakes ( $h$ designates the depth of the seismic center below the Earth's surface). One has to underline that the number of such earthquakes close to the chosen vertical sounding station during the time of the continuous operation of the station is not large enough to obtain a good statistical confirmation of the obtained results, but it nevertheless allows one to reveal a few common features and tendencies of seismoionospheric phenomena. In the paper earthquakes with magnitude $M \geq 5.5$, which occurred at distances less than $500 \mathrm{~km}$ from the vertical sounding station, were considered.

Data of the Dushanbe vertical sounding station (coordinates $\varphi=38.5^{\circ} \mathrm{N}, \lambda=68.8^{\circ} \mathrm{E}$ ) for the time interval from 1985 until 1990 were used. Only nighttime values (to avoid influences of the solar radiation) of the ionospheric parameters $f o \mathrm{~F} 2, f o \mathrm{Es}, f b \mathrm{Es}$, and Es-spread (Es-spread means 
a diffusive track of an Es-layer on an ionogram) were selected for the analysis. The nighttime was considered to be the time from 18:00 LT till 06:00 LT. Vertical sounding was performed in intervals of fifteen minutes. The time dependence of ionospheric parameters for every earthquake was studied during eight nights, six nights before the event and two nights after the event.

If the earthquake took place in the night after 24:00 LT, the night was considered to be a " -1 " night. If the earthquake happened at night before 24:00 LT, the night was designated by $(+1)$. In cases when the preseismic periods of two different earthquakes coincided partially, only the first earthquake was used in the analysis. Thirty-six earthquakes with $M \geq 5.5$ were complied with the requirements of the performed analysis. With much regret the authors have to point out that data for all four listed ionospheric parameters were not available for each earthquake. Thus when investigating different ionospheric effects the authors had to consider different numbers of earthquakes. The columns in Table 1 contain the parameters of the analysed earthquakes, date and time coordinates (latitude and longitude), the depth of the epicenter $h$ and the magnitude $M$. The seismological online catalogue of Obninsk was used. The availability of the plasmaparameters is displayed by the sign " + " in the table.

To reveal seismoionospheric effects the data for every earthquake were divided into four groups: $(-6,-5),(-4$, $-3),(-2,-1)$ and $(+1,+2)$ nights, correspondingly. Averaging inside each group was made for each earthquake (i.e. the mean value of the parameter in question was found for the $(-6,-5)$ night and so on) for the parameters $f o \mathrm{~F} 2, f b \mathrm{Es}$, and the coefficient of semi-transparency $\Delta f b$ Es $=(f o$ Es$f b$ Es) / $f b$ Es. The results were normalized by the mean value of all four groups. So the modification of dimensionless parameters was analysed for each earthquake. Furthermore, the superimposed epoch method was used to obtain general dependencies separately for deep $(h>33 \mathrm{~km})$ and crust $(h \leq 33 \mathrm{~km})$ earthquakes. After this procedure, the precision of the mean value was defined by the standard deviation from the mean value.

\section{The morning decrease of $f o \mathbf{F} 2$}

The $f o \mathrm{~F} 2$ frequency is one of the most important ionospheric parameters, often analysed in seismoionospheric studies. It can be measured either by satellites or by vertical sounding stations, and all sounding stations in the world present the hourly $f o \mathrm{~F} 2$-values. The decrease of $f o \mathrm{~F} 2$ in the morning hours $1-5$ days before strong earthquakes was already discussed by Pulinets (1998). In the present paper, the time dependence of $f o \mathrm{~F} 2$ is analysed separately for deep and crust earthquakes. The $f o \mathrm{~F} 2$-parameter is averaged over the morning hours (00:00-06:00 LT). It should be mentioned that the number of deep earthquakes is 20 , and the number of crust earthquakes is 10 in this analysis. Figure 1 shows the results which were found using the superimposed epoch method for four groups of nights. From the figure follows

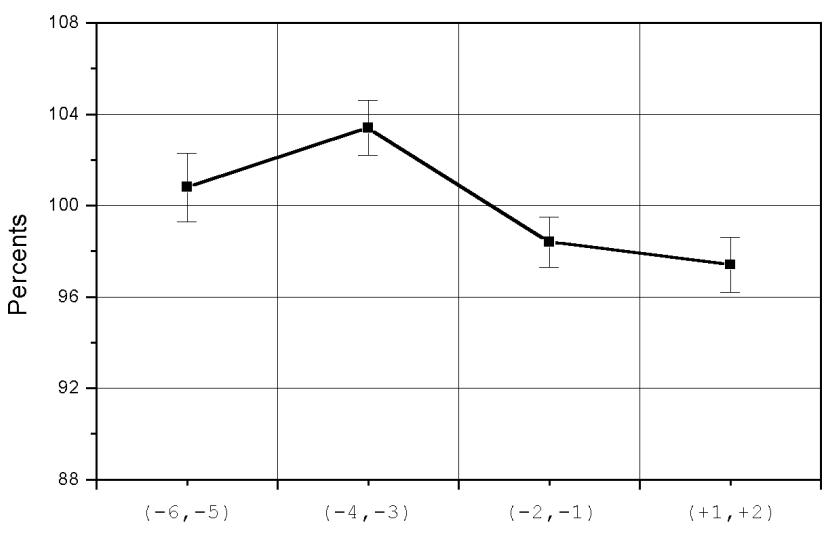

Fig. 1. Time dependence of the critical frequency $f o \mathrm{~F} 2$ averaged over the morning hours (00:00 LT-06:00 LT). The results were obtained using the superimposed epoch method for 30 earthquakes (20 deep and 10 crust events) with magnitude $M=5.5$ and $R<500 \mathrm{~km}$. The results are visualized for four groups of nights, the so-called $(-6,-5),(-4,-3),(-2,-1),(+1,+2)$ nights. The presented frequency values are normalized by the mean value over the four groups.

that there exists a tendency for the morning $f o \mathrm{~F} 2$-values to decrease from the $(-4,-3)$ nights to the $(-2,-1)$ nights. Variations are not significant for other groups. Thus the characteristic time of decrease is around 2 days. An analysis performed separately for deep and crust earthquakes demonstrated the same tendency, but due to the smaller numbers of earthquakes, the results are less significant. Qualitatively, the effect is stronger for deep earthquakes.

\section{The decrease of the average nighttime values of $f b \mathrm{Es}$}

It was proven (Liperovsky et al., 2000b) that the $f b$ Es parameter averaged over the night hours decreases one day before an earthquake. The effect takes place for earthquakes with $M \geq 5$ at distances $R<500 \mathrm{~km}$ from the epicenters. Now it is proposed that the preparation time for earthquakes with $M \geq 5.5$ is yet larger than 1-2 nights, and so the characteristic time scale of the decrease of the parameter $f b \mathrm{Es}$ may be different.

In the present analysis, data were available for 26 earthquakes. In the cases with an absence of an Es-layer trace on the ionogram, the $f b$ Es-value is assumed to be equal to the sensitivity threshold of the ionospheric station. As in the previous case, averaged values were obtained for the four groups of nights, then the values were normalized and the superimposed epoch method was used. The results are presented in Fig. 2. A tendency for the decrease of the nighttime $f b$ Es from the $(-4,-3)$ nights to the $(-2,-1)$ nights exists; variations are not significant for other groups. Analyses performed separately for 15 deep and 11 crust earthquakes demonstrated the same tendency in both cases. Qualitatively, the effect is stronger for deep earthquakes. 
Table 1. Parameters of earthquakes used for the analysis in the present paper

\begin{tabular}{|c|c|c|c|c|c|c|c|c|c|}
\hline date & UT & latitude & longitude & $\mathrm{h}$ & M & $f o \mathrm{~F} 2$ & $f b \mathrm{Es}$ & $\begin{array}{c}\text { semi- } \\
\text { transparency }\end{array}$ & Es-spread \\
\hline 03.10 .85 & $18: 07$ & $36.57^{\circ} \mathrm{N}$ & $71.64^{\circ} \mathrm{E}$ & 90 & 5.5 & - & + & + & + \\
\hline 17.01 .88 & $3: 36$ & $36.23^{\circ} \mathrm{N}$ & $70.83^{\circ} \mathrm{E}$ & 99 & 5.5 & + & + & + & + \\
\hline 03.08 .88 & $5: 43$ & $36.51^{\circ} \mathrm{N}$ & $71.01^{\circ} \mathrm{E}$ & 197 & 5.5 & + & + & + & + \\
\hline 09.09 .88 & $21: 12$ & $36.49^{\circ} \mathrm{N}$ & $71.43^{\circ} \mathrm{E}$ & 84 & 5.5 & + & + & + & + \\
\hline 19.11 .89 & $4: 29$ & $36.70^{\circ} \mathrm{N}$ & $70.83^{\circ} \mathrm{E}$ & 196 & 5.5 & + & + & + & + \\
\hline 03.09 .90 & $2: 40$ & $36.49^{\circ} \mathrm{N}$ & $70.73^{\circ} \mathrm{E}$ & 200 & 5.5 & + & + & + & + \\
\hline 11.03 .86 & $23: 07$ & $36.18^{\circ} \mathrm{N}$ & $70.72^{\circ} \mathrm{E}$ & 183 & 5.6 & + & - & - & + \\
\hline 26.10 .88 & $2: 15$ & $36.57^{\circ} \mathrm{N}$ & $70.94^{\circ} \mathrm{E}$ & 214 & 5.6 & + & + & + & + \\
\hline 06.05 .89 & $21: 14$ & $36.50^{\circ} \mathrm{N}$ & $70.15^{\circ} \mathrm{E}$ & 212 & 5.6 & + & + & + & + \\
\hline 27.04 .85 & $1: 31$ & $38.73^{\circ} \mathrm{N}$ & $73.15^{\circ} \mathrm{E}$ & 94 & 5.7 & + & - & - & - \\
\hline 13.10 .86 & $16: 11$ & $36.16^{\circ} \mathrm{N}$ & $70.97^{\circ} \mathrm{E}$ & 102 & 5.7 & - & + & - & + \\
\hline 15.09 .86 & $21: 42$ & $36.96^{\circ} \mathrm{N}$ & $71.05^{\circ} \mathrm{E}$ & 100 & 5.8 & + & - & - & + \\
\hline 02.04 .87 & $18: 45$ & $36.63^{\circ} \mathrm{N}$ & $71.16^{\circ} \mathrm{E}$ & 118 & 5.8 & + & - & - & + \\
\hline 07.05 .86 & $23: 25$ & $36.34^{\circ} \mathrm{N}$ & $70.75^{\circ} \mathrm{E}$ & 211 & 5.9 & + & - & - & + \\
\hline 26.04 .86 & $14: 15$ & $36.63^{\circ} \mathrm{N}$ & $71.13^{\circ} \mathrm{E}$ & 184 & 6.0 & + & - & - & + \\
\hline 26.03 .88 & $22: 58$ & $38.33^{\circ} \mathrm{N}$ & $73.26^{\circ} \mathrm{E}$ & 106 & 6.0 & + & + & + & + \\
\hline 05.05 .87 & $15: 40$ & $36.30^{\circ} \mathrm{N}$ & $70.75^{\circ} \mathrm{E}$ & 189 & 6.1 & + & - & - & + \\
\hline 03.10 .87 & $11: 00$ & $36.60^{\circ} \mathrm{N}$ & $71.47^{\circ} \mathrm{E}$ & 93 & 6.1 & + & - & - & + \\
\hline 13.07 .90 & $14: 20$ & $36.62^{\circ} \mathrm{N}$ & $70.75^{\circ} \mathrm{E}$ & 204 & 6.1 & + & + & + & + \\
\hline 25.10 .90 & $4: 54$ & $35.22^{\circ} \mathrm{N}$ & $70.53^{\circ} \mathrm{E}$ & 110 & 6.1 & - & + & + & + \\
\hline 24.07 .89 & $3: 27$ & $36.07^{\circ} \mathrm{N}$ & $71.19^{\circ} \mathrm{E}$ & 88 & 6.2 & + & + & + & + \\
\hline 15.05 .90 & $14: 25$ & $35.92^{\circ} \mathrm{N}$ & $70.53^{\circ} \mathrm{E}$ & 109 & 6.2 & - & + & + & + \\
\hline 29.07 .85 & $7: 54$ & $36.35^{\circ} \mathrm{N}$ & $70.94^{\circ} \mathrm{E}$ & 114 & 6.6 & + & - & + & + \\
\hline 05.02 .90 & $5: 16$ & $37.08^{\circ} \mathrm{N}$ & $71.29^{\circ} \mathrm{E}$ & 89 & 6.6 & + & + & + & + \\
\hline 24.05 .86 & $15: 31$ & $35.90^{\circ} \mathrm{N}$ & $69.04^{\circ} \mathrm{E}$ & 3 & 5.5 & + & - & - & + \\
\hline 21.12 .88 & $8: 21$ & $41.41^{\circ} \mathrm{N}$ & $72.16^{\circ} \mathrm{E}$ & 3 & 5.5 & + & + & + & + \\
\hline 22.01 .89 & 23:02 & $38.57^{\circ} \mathrm{N}$ & $68.69^{\circ} \mathrm{E}$ & 5 & 5.5 & + & + & + & + \\
\hline 09.01 .88 & $3: 55$ & $39.18^{\circ} \mathrm{N}$ & $71.46^{\circ} \mathrm{E}$ & 3 & 5.6 & + & + & + & + \\
\hline 14.12 .88 & $11: 45$ & $39.24^{\circ} \mathrm{N}$ & $71.76^{\circ} \mathrm{E}$ & 3 & 5.6 & + & + & + & + \\
\hline 19.04 .90 & $22: 41$ & $34.12^{\circ} \mathrm{N}$ & $69.64^{\circ} \mathrm{E}$ & 33 & 5.6 & - & + & + & + \\
\hline 20.07 .88 & $6: 20$ & $37.12^{\circ} \mathrm{N}$ & $72.98^{\circ} \mathrm{E}$ & 3 & 5.7 & + & + & + & + \\
\hline 25.09 .88 & $20: 52$ & $37.26^{\circ} \mathrm{N}$ & $71.90^{\circ} \mathrm{E}$ & 3 & 5.7 & + & + & - & + \\
\hline 03.11 .90 & $16: 39$ & $39.04^{\circ} \mathrm{N}$ & $71.36^{\circ} \mathrm{E}$ & 3 & 5.9 & - & + & + & + \\
\hline 13.10 .85 & $15: 59$ & $40.52^{\circ} \mathrm{N}$ & $69.75^{\circ} \mathrm{E}$ & 3 & 6.0 & + & + & + & + \\
\hline 05.03 .90 & $20: 46$ & $36.55^{\circ} \mathrm{N}$ & $73.22^{\circ} \mathrm{E}$ & 3 & 6.0 & + & + & + & + \\
\hline 25.03 .90 & $14: 17$ & $37.06^{\circ} \mathrm{N}$ & $73.06^{\circ} \mathrm{E}$ & 3 & 6.3 & + & + & + & + \\
\hline
\end{tabular}

\section{Modification of $f b$ Es semi-transparency coefficient}

It is of great importance to find out if there exists a phenomenon which is only peculiar for crust earthquakes. These earthquakes are the most destructive ones and the problem of their prognosis has to be solved first. The authors proposed that the semi-transparency coefficient $\Delta f b \mathrm{Es}=(f o \mathrm{Es}-$ $f b \mathrm{Es}) / f b \mathrm{Es}$, which is very variable by itself, is sensitive to crust earthquake preparation processes. This coefficient characterizes the degree of turbulence of the E-region. It was supposed (Gorbunova and Shved, 1984; Takefu, 1989) that the reason for the existence of large $\Delta f b$ Es values is the radio wave scattering on small-scale (tens of meters) irregularities of the electron density. In Fig. 3, the results of the semi-transparency coefficient analysis are presented separately for 15 deep and 10 crust earthquakes. The value of the semi-transparency coefficient increases in the $(-4,-3)$,
$(-2,-1)$ nights in the case of crust earthquakes. For deep earthquakes $\Delta f b$ Es slightly varies within the error bounds.

\section{Spread-Es increase}

The Es-spread effect in the mid-latitude ionosphere has been studied by Bowman (1985) and Liperovskaya et al. (2000). The Es-spread effect consists of the diffusivity of the Es-layer traces on the ionograms, and it apparently reflects the processes of large-scale (few hundred meters) instabilities in the sporadic layers. The Es-spread is a rather rare phenomenon and it is extremely seldom detected by ionospheric stations. Es-spread is closely related to the solar activity and rarely observed in years of solar maximum (Bowman, 1985; Liperovskaya et al., 2000). Usually, Es-spread is observed at low values of the critical frequency $f b \mathrm{Es}(1-2 \mathrm{MHz})$; it has a sea- 


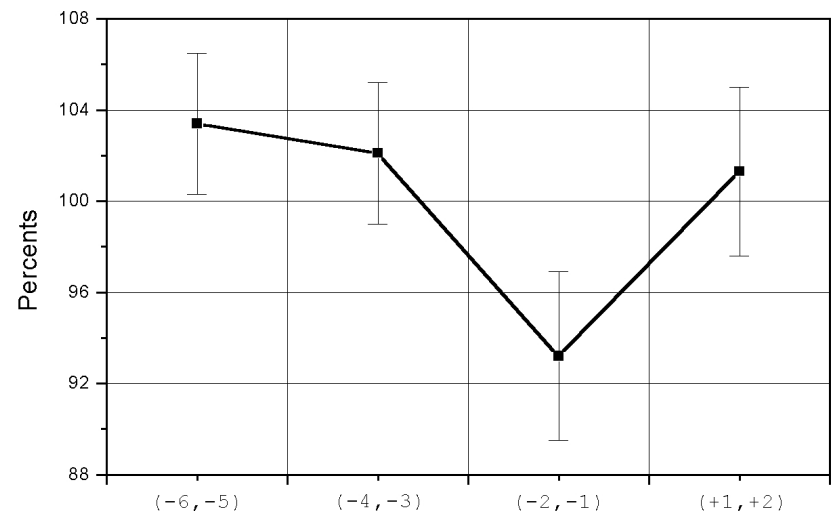

Fig. 2. Time dependence of the mean nighttime (18:00 LT06:00 LT) $f b$ Es frequency. The results were observed by the superimposed epoch method for 26 earthquakes (15 deep and 11 crust ones) with magnitude $M=5.5$ and $R<500 \mathrm{~km}$. The $f b$ Es frequency is visualized for four groups of nights, the so-called $(-6,-5),(-4,-3),(-2,-1),(+1,+2)$ nights, and normalized by the mean value over the four groups.

sonal dependence and it occurs more often in winter than in summer. The characteristic time of Es-spread existence is of the order of a few minutes (Liperovsky et al., 2000b).

All these facts allow one to assume that Es-spread is predominantly connected with sporadic layer turbulence, which is caused by neutral gas turbulization excited by atmospheric waves with periods of several minutes propagating from the Earth's surface or/and from the lower atmosphere to the ionosphere. Danilov et al. (1987) assumed that the Es-spread could be associated with meteorological effects in the atmosphere. Further, in the paper by Alimov et al. (1989), it was discussed that the disturbances propagating from the Earth's surface to the ionosphere during earthquake preparation can reach the ionosphere and, as a result, increase the probability of the Es-spread appearance. It was expected that Esspread may become a prognostic indicator of earthquakes. Based on a six-year data sample, Liperovskaya et al. (2000) published a statistical analysis which demonstrated that in case of earthquakes with magnitude $M>4.5$ at a distance $R<500 \mathrm{~km}$ from the vertical sounding (VS) stations, the probability of Es-spread observations is independent of the earthquake preparation processes occurring 1-3 days before a shock. A number of earthquakes, however, was accompanied by a distinct increase of Es-spread. So it is interesting to analyse the effect separately for stronger $(M \geq 5.5)$ earthquakes and shorter distances to the VS stations.

There are no distinct links between Es-spread and the moment of the earthquake; only five earthquakes (from a total of twenty-one events occurring at nighttime) were accompanied by Es-spread for a few hours before the shock.

Analysing each earthquake, the total number of Es-spread observations was obtained for the $(-6,-5,-4)$ nights and the $(-3,-2,-1)$ nights before each event. Thus for each earthquake it was determined whether the Es-spread observations in the $(-3,-2,-1)$ nights increased or decreased in
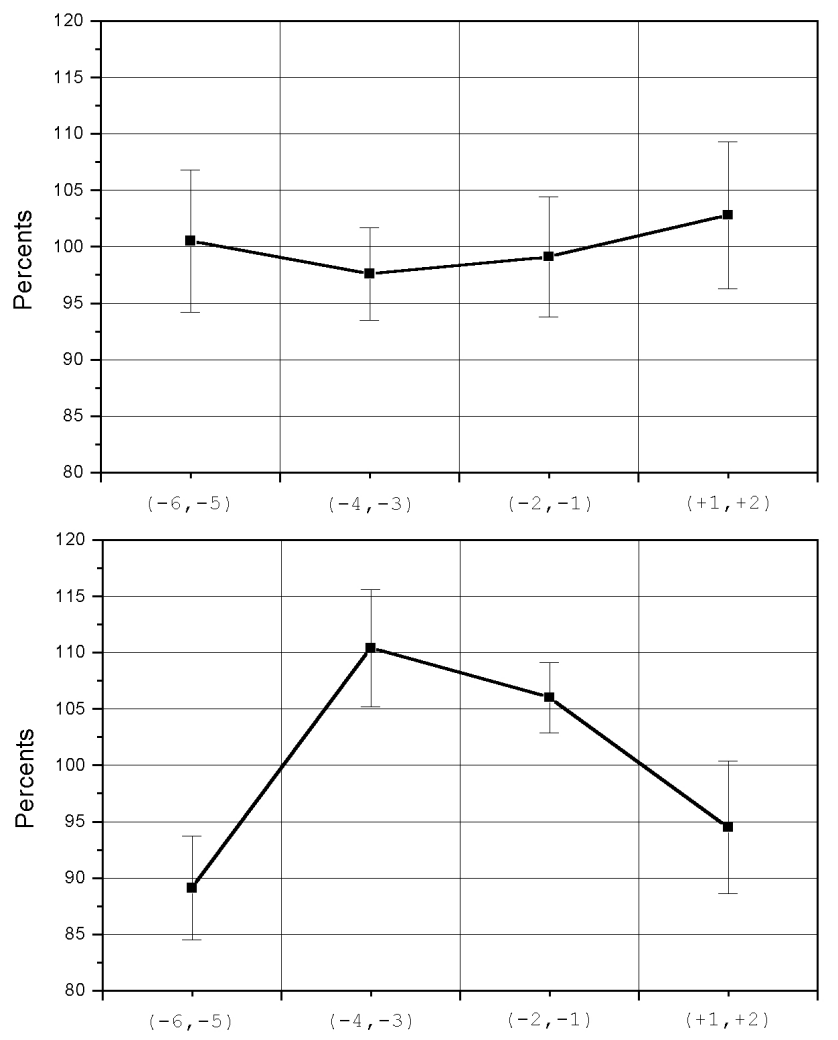

Fig. 3. Time dependence of the mean night-time (18:00 LT-06:00 LT) coefficient of semi-transparency $\Delta f b \mathrm{Es}=(f o \mathrm{Es}-f b \mathrm{Es}) / f b \mathrm{Es}$. The results were obtained by the superimposed epoch method for (a) 15 deep and (b) 10 crust earthquakes with magnitude $M=5.5$ and $R<500 \mathrm{~km}$. The coefficient of semi-transparency is visualized for four groups of nights, the so-called $(-6,-5),(-4,-3)$, $(-2,-1),(+1,+2)$ nights, and normalized by the mean value over four groups.

comparison with the $(-6,-5,-4)$ nights. For the next step this comparison was provided separately for deep and crust earthquakes for three magnitude intervals (Table 2). It was found that for earthquakes with magnitudes $M \geq 5.8$, Esspread appeares more often during the $(-3,-2,-1)$ nights. For 17 earthquakes which were used in the analysis, an increase occurred in 10 cases, in two cases a decrease was obtained, and in five cases no variations could be found.

In a more accurate Es-spread effect analysis the earthquakes with magnitudes $5.0 \leq M \leq 5.4$ and $5.5 \leq M \leq 5.7$ were also considered. The results allow one to draw the conclusion that an increase in Es-spread takes place only for strong earthquakes.

The analysis also shows the following tendency: for the most deep $(h>33 \mathrm{~km})$ earthquakes with $5.5 \leq M \leq$ 6.6 the number of Es-spread phenomena increases from the $(-6,-5,-4)$ nights to the $(-3,-2,-1)$ nights (they increase in 13 cases, decrease in 4 cases, and no effect occurred in 6 cases).

One may suppose that this tendency is connected with the differences between the absorption of wideband earth- 
Table 2. Es-spread effect

\begin{tabular}{|c|c|c|c|c|c|c|c|c|c|}
\hline \multirow[t]{2}{*}{$\begin{array}{l}\text { Magnitude of } \\
\text { the earthquakes }\end{array}$} & \multicolumn{3}{|c|}{$\begin{array}{l}\text { Increasing in the } \\
(-3,-2,-1) \text { nights }\end{array}$} & \multicolumn{3}{|c|}{$\begin{array}{l}\text { Decreasing in the } \\
(-3,-2,-1) \text { nights }\end{array}$} & \multicolumn{3}{|c|}{$\begin{array}{l}\text { Equal in the }(-3,-2,-1) \\
\text { and }(-6,-5,-4) \text { nights }\end{array}$} \\
\hline & deep & crust & $\Sigma$ & deep & crust & $\Sigma$ & deep & crust & $\Sigma$ \\
\hline $5.0-5.4$ & 8 & 11 & 19 & 13 & 8 & 21 & 7 & 0 & 7 \\
\hline $5.5-5.7$ & 6 & 1 & 7 & 2 & 4 & 6 & 2 & 3 & 5 \\
\hline $5.8-6.6$ & 7 & 3 & 10 & 2 & 0 & 2 & 4 & 1 & 5 \\
\hline
\end{tabular}

quake preparation acoustic emissions from deep and crust eartquakes. It is quite possible that all the "short-wave" parts of the deep earthquake emission spectra dissipates on the way to the Earth's surface, and thus only "long-period" waves $(T \sim 10-100 \mathrm{~s})$ appear in the ionosphere and generate effects of the same characteristic time in the Es-layer. On the other hand, the semi-transparency coefficient $\Delta f b$ Es varies due to the "short-wave" acoustic noise ( $T \leq 1 \mathrm{~s})$.

In the monographs (Hayakawa and Fujinawa, 1994; Hayakawa, 1999) and the review (Liperovsky et al., 2000a), many hypotheses on mechanisms of seismoionospheric coupling are presented. All hypotheses could be conditionally divided into two groups - the "acoustic" and the "electromagnetic". In acoustic models it is supposed that acoustic disturbances caused by lithospheric processes appear in the near-surface neutral atmosphere. The acoustic and acoustic-gravity waves further penetrate up to ionospheric altitudes and, due to collisional processes, cause disturbances in the plasma of the ionosphere. In a number of "electromagnetic" models it is supposed that currents, spots of electrical charges and electromagnetic noise radiation arise on the Earth's surface due to processes of earthquake preparation. The parameters of the ionosphere are further modified under the influence of an electromagnetic field of lithospheric origin. A quantitative theory of a possible lithosphere-ionosphere coupling has not been developed up to now. The dependence on the depth of the epicenters of the earthquakes is not taken into account in any hypothesis, so up to now, none of the available hypotheses could satisfactorily interpret the obtained results.

\section{Conclusions}

In the present work, a statistical analysis of ionospheric phenomena before earthquakes with $M \geq 5.5$ is performed. The conventional separation of strong earthquakes into so-called "deep" and "crust" ones is introduced, and separate analyses of related seismoionospheric phenomena are done. The difference between the seismoionospheric effects of these groups of earthquakes is revealed; it is perhaps connected with different mechanisms of the transfer of a part of the earthquake preparation energy from the earthquake preparation region to the ionosphere. However, the analysis of the physical mechanisms of energy transfer was not the intent of the paper, since from the point of view of the authors, nowa- days even the morphological features of seismoionospheric effects of strong earthquakes are not yet sufficiently studied.

A statistical analysis of Es-spread effects as earthquake precursors is performed in the work. Es-spread data are very rare, with only a few independently working researchers deriving them from ionograms. The analysis of the Es-spread observations shows that Es-spread increases 1-3 days before earthquakes with $M \geq 5.5$, the effect is stronger for deep earthquakes.

In addition, the semi-transparency of the Es-layers is studied. The semi-transparency can also be used to demonstrate seismoionospheric effects. It should be noted that the value of the semi-transparency depends on the presence of smallscale (meters and tens of meters) plasma inhomogeneities of the Es-layers. It was found in this work that the semitransparency increases 1-4 days before crust earthquakes. But it does not change before deep earthquakes.

Furthermore, a statistical analysis of the $f b$ Es-frequency is performed for earthquakes with $M \geq 5.5$. Earlier it was revealed that the mean nighttime value of $f b$ Es decreases from the $(-2)$ night to the $(-1)$ night for earthquakes with $5 \leq M$. It is self-evident that earthquakes with $5 \leq M \leq$ 5.5 form a large part of the earthquakes with $M \geq 5$. The results of the present investigation also showed that they play a dominant role. In the paper, the characteristic time scale of the decrease of the mean $f b$ Es-frequency is determined for earthquakes with $M \geq 5.5$; it equals about 2 days (not 1 , as for earthquakes with $5 \leq M \leq 5.5$ ).

The morning decrease of the $f o \mathrm{~F} 2$-frequency is also statistically investigated for the first time. It possesses a time scale of about two days.

It is found that the decreases in the $f o \mathrm{~F} 2$ and $f b$ Es parameters take place for both deep and crust earthquakes.

Our analyses allow one to assume that the semitransparency coefficient is the most perspective parameter for a future earthquake prediction system.

Acknowledgements. C.-V. M. thanks the Ministerium für Wissenschaft, Forschung und Kultur des Landes Brandenburg for making it possible to work on the given topic.

\section{References}

Alimov, O. A., Roubtsov, L. N., Gokhberg, M. B., Liperovskaia, E. V., Gufeld, I. L., and Liperovsky, V. A.: Anomalous charac- 
teristic of the middle latitude Es layer before earthquakes, Phys. Earth. and Planet. Inter., 57, 76-81, 1989.

Bowman, G. G.: Some aspects of mid-latitude spread Es and its relationship with spread F, Planet. Space Sci., 33, 9, 1081, 1985.

Danilov, A. D., Kazimirovsky, E. S., Vergasova G. V., and Khachikyan, G. Ya.: Meteorological Effects in the Ionosphere, Leningrad, Gidrometeoizdat, (in Russian), 1987.

Gokhberg, M. B., Morgounov, V. A., and Pokhotelov, O. A.: Earthquake Prediction: Seismoelectromagnetic Phenomena, Gordon and Breach Science Publishers, Reading-Philadelphia, 1995.

Gorbunova, T. A. and Shved G. M.: The analysis of Es-layer semitransparency as an indicator of turbulence with dynamically homogeneous conditions, Geomagnetism and Aeronomy, 24, 1, 30-34, 1984.

Hayakawa, M., (Ed): Atmospheric and Ionospheric Electromagnetic Phenomena Associated with Earthquakes, Terra Sci. Pub. Co., Tokyo, 1999.

Hayakawa, M. and Fujinawa, Y., (Eds): Electromagnetic Phenomena Related to Earthquake Prediction, Terra Sci-Pub. Co., Tokyo, 1994.

Liperovskaya, E. V., Silina, A. S., Saidshoev, A., Liperovsky, V. A., Meister, C.-V., and Vasil'eva, N. E.: On the effect of spread Es of night sporadic layers, Geomagnetism and Aeronomy, 40, 1, 112-114, 2000.

Liperovskiy, V. A., Pokhotelov, O. A., Liperovskaya, Ye. V.,
Rubtsov, L. N., Fomichev, Yu. P., and Saydshoyev, A.: Patterns of some seismo-ionospheric effects, Doclady RAN, 331A, 6, 24 28,1995

Liperovsky, V. A., Meister, C.-V., Popov, K. V., Liperovskaya, E. V., Molchanov, O. A., and Silina, A. S.: On the time scales of some seismoionosphere effects, International Workshop on Seismoelectromagnetics, 2000 of NASDA, Programs and Abstracts, 1922 September 2000, The University of Electro-Communications Chofu-City, Tokyo, Japan, 178-182, 2000b.

Liperovsky, V. A., Pokhotelov, O. A., Liperovskaya, E. V., Parrot, M., Meister, C.-V., and Alimov, O. A.: Modification of sporadic E-layers caused by seismic activity, Surv. in Geophys., 21, 449486, 2000a.

Liperovsky, V. A., Pokhotelov, O. A., and Shalimov, S. L.: Ionospheric precursors of earthquakes, Nauka, Moscow, (in Russian), 1992.

Ondoh, T.: Seismo-ionospheric phenomena, Adv. Space Res., 26, 8, 1267-1272, 2000.

Pulinets, S. A.: Strong earthquake prediction possibility with the help of topside sounding from satellites, Adv. Space Res., 21, 3, 445-458, 1998.

Takefu, M.: Bragg scattering of radio waves by ionospheric wavelike irregularities, J. Geomagnetism and Geoelectricity, 41, 8, 647-672, 1989. 